\title{
Spinal Vascular Disorder
}

National Cancer Institute

\section{Source}

National Cancer Institute. Spinal Vascular Disorder. NCI Thesaurus. Code C35626.

A disorder that is caused by pathologic changes in the spinal vasculature. 